\title{
Erratum to: Intraocular pressure changes during hemodialysis
}

\author{
Vassilios Liakopoulos $^{1} \cdot$ Paraskevi Demirtzi $^{1} \cdot$ Dimitrios G. Mikropoulos $^{2,3}$.
}

Konstantinos Leivaditis ${ }^{1} \cdot$ Evangelia Dounousi $^{1} \cdot$ Anastasios G. P. Konstas $^{2,3}$

Published online: 2 September 2015

(C) Springer Science+Business Media Dordrecht 2015

\section{Erratum to: Int Urol Nephrol \\ DOI 10.1007/s11255-015-1043-8}

In the original article, the name of second author has been wrongly published. The correct name should be Paraskevi Demirtzi. The original article has been updated accordingly.

The online version of the original article can be found under doi:10.1007/s11255-015-1043-8.

Vassilios Liakopoulos

liakopul@otenet.gr

1 Division of Nephrology and Hypertension, 1st Department of Internal Medicine, AHEPA Hospital, School of Medicine, Aristotle University of Thessaloniki, 1 St. Kyriakidi Street, 54636 Thessaloniki, Greece

2 3rd University Department of Ophthalmology, School of Medicine, Aristotle University of Thessaloniki,

Thessaloniki, Greece

3 Ophthalmica Eye Institute, Thessaloniki, Greece 